\title{
The Nephrotoxic Ifosfamide-Metabolite Chloroacetaldehyde Interferes with Renal Extracellular Matrix Homeostasis
}

\author{
Andreas Benesic ${ }^{\mathrm{a}}$ Gerald Schwerdt ${ }^{\mathrm{b}}$ Isabell Hennemeier ${ }^{\mathrm{b}} \quad$ Christoph Sauvant $^{\mathrm{c}}$ \\ Sigrid Mildenberger ${ }^{\mathrm{b}} \quad$ Michael Gekle $^{\mathrm{b}}$ \\ aMedizinische Klinik und Poliklinik 2, Universitätsklinikum Großhadern, Ludwig-Maximilians-Universität \\ München, bJulius-Bernstein-Institut für Physiologie, Martin-Luther-Universität Halle-Wittenberg, \\ 'Klinik für Anästhesiologie und Operative Intensivmedizin, Martin-Luther-Universität Halle-Wittenberg, \\ Germany
}

\section{Key Words}

Renal fibrosis $\bullet$ Extracellular matrix $\bullet$ Chloroacetaldehyde $\bullet$ Ifosfamide $\bullet$ Nephrotoxicity

\begin{abstract}
Background/Aims: Chronic renal proximal tubule dysfunction after therapy with the antineoplastic agent ifosfamide (IFO) is often attributed to the metabolite chloroacetaldehyde (CAA). Chronic IFO-nephropathy is reported to result in tubulointerstitial fibrosis and inflammation. Methods: To elucidate possible effects of CAA on extracellular matrix homeostasis, we investigated the action of CAA on markers of extracellular matrix (ECM) homeostasis in human proximal tubule cells (RPTEC) by use of direct ELISA for extracellular collagens and gelatin zymography. Results: An increase in type III collagen and a decrease in type IV collagen abundance in the media of RPTEC could be observed after exposure to CAA in clinically relevant concentrations. CAA increased intracellular type III and decreased intracellular type IV collagen. MMP-2 activity was decreased but MMP-9 activity unchanged. The enhanced CAA-induced collagen III formation could be attenuated by the intracellular $\mathrm{Ca}^{2+}$-chelator BAPTA-AM, the PKA-antagonist $\mathrm{H}-89$ and by extracellular acidification. CAA-induced collagen III abundance was enhanced by $\mathrm{db}-\mathrm{CAMP}$ and IBMX and by protein overload. Conclusions: CAA exerts profibrotic effects on RPTEC dependent on $\mathrm{Ca}^{2+}$ and CAMP/PKA-signaling. These effects are enhanced by additional protein burden and attenuated by acidification.
\end{abstract}

Copyright $\odot 2014$ S. Karger AG, Basel

\section{Introduction}

Chloroacetaldehyde (CAA) is a metabolite of the cancer therapeutic ifosfamide (IFO) generated mainly in liver by cytochrome P450-dependent mechanisms [1]. IFO is included in therapy protocols for the treatment of malignant solid tumors, especially in pediatric 
oncology, with response rates up to $80 \%$ [2]. Yet, there is a significant number of patients developing chronic renal dysfunction, sometimes even years after the end of treatment $[3,4]$. The predominant target for IFO-induced renal disease is the proximal tubule $[5,6]$. The severity of renal impairment ranges from mild renal tubular acidosis (in up to $40 \%$ of all patients) to full blown Fanconi-syndrome (in up to $5 \%$ of all patients) $[3,7,8]$. In pediatric patients treated with IFO wasting of phosphate by damaged proximal tubules often requires phosphate substitution to prevent hypophosphatemic rickets [3]. Additionally, the toxic effects of IFO treatment can persist over a long time period in children [9]. Thus, renal toxicity of IFO is of concern in oncology patients and especially in children. Until now, there are few prognostic parameters to identify patients who will develop chronic nephrotoxicty, since acute and chronic damage are not well correlated [10]. Furthermore, the mechanisms by which IFO leads to proximal tubular damage are poorly understood. Among IFO and its metabolites, CAA is most probably responsible for chronic renal disease [11-14]. Cell culture studies could show impairment of several transport mechanisms by CAA in renal proximal tubule cells and a concentration-dependent necrotic rather than apoptotic cell death [1519]. Recently we could provide evidence for cAMP-dependent alterations in $\mathrm{Ca}^{2+}$-signaling by CAA in human proximal tubule cells in primary culture [20]. CAA acts as a sulfhydryl reagent and thereby impairs the proper function of proteins necessary for the balance of proliferation and apoptosis by inhibition of caspases. We could also show that CAA inhibits cathepsin B, a lysosomal cysteine protease of importance for digestion of endocytosed protein [21]. Depletion of non-protein-sulfhydryl groups such as reduced glutathione (GSH) impairs the capacity of the cells to scavenge free radicals, thereby increasing the susceptibility to oxidative stress. The latter mechanism should account for acute toxicity that is frequently observed during IFO-infusion. It may also be a mechanism of antitumor action of ifosfamide [22]. Consequently, providing alternative free sulfhydryl group-carrying molecules protects renal cells in culture (GSH, mesna or cysteine $[19,23]$ ) and probably also in vivo (by $\mathrm{N}$-acteylcysteine in combination with its antioxidative action [24]). Inhibition of cysteine proteases and disturbed $\mathrm{Ca}^{2+}$-handling do not necessarily lead to acute renal cell death, but are capable to induce chronic functional modifications leading to proximal tubule cell dysfunction, finally resulting in organ damage.

There are several case reports of pediatric and adult patients who developed chronic IFO-nephrotoxicity presenting as tubulointerstitial nephritis and fibrosis [25-27]. The hallmarks of chronic tubulointerstitial nephritis are chronic inflammatory events and altered extracellular matrix composition, which reinforce each other [28]. This vicious circle leads to epithelial mesenchymal transdifferentiation of proximal tubule cells, resulting in renal fibrosis in combination with impaired organ function. The major players in tubulointerstitial fibrosis are the fibrillar collagens type I and type III, which are often found to be increased in fibrotic disease [29]. Increases in collagen type IV as a constituent of the basal membrane are considered to be responsible for glomerular basement thickening, as it is found in diabetic nephropathy [30].

The purpose of this study was to identify possible profibrotic effects in human renal cells provoked by CAA and the signaling mechanisms involved. To work with a cell culture model in proximity to the clinical situation, human renal proximal tubule cells in primary culture (RPTEC) were used.

\section{Materials and Methods}

\section{Cell culture}

Human renal proximal tubule epithelial cells in primary culture (RPTEC) were purchased from Clonetics $₫$ (Cambrex Bioproducts) via CellSystems $®$, 53562 St. Katharinen, Germany. Cells were cultivated in plastic culture dishes (growth area $75 \mathrm{~cm}^{2}$ ) in Ham F-12/Dulbecco's modified Eagle's medium (DMEM), supplemented with $1.1 \mathrm{~g} / \mathrm{l} \mathrm{NaHCO}_{3}, 3.57 \mathrm{~g} / \mathrm{l}$ 4-(2-hydroxyethyl)-1-piperazineethanesulphonic acid (HEPES), $5 \mathrm{mg} / \mathrm{l}$ human apo-transferrin, $5 \mathrm{mg} / \mathrm{l}$ (bovine)insulin, $500 \mu \mathrm{g} / \mathrm{l}$ hydrocortisone, $10 \mu \mathrm{g} / \mathrm{l} \mathrm{mouse} \mathrm{EGF,} 5 \mu \mathrm{g} / \mathrm{l}$ 
$\mathrm{Na}^{+}$-selenite, $0.5 \%$ fetal calf serum (Biochrom, Berlin, Germany), $6.5 \mu \mathrm{g} / \mathrm{l}$ thyroxin and $500 \mu \mathrm{g} / \mathrm{l}$ epinephrine under standard cell culture conditions $\left(37^{\circ} \mathrm{C}, 5 \% \mathrm{CO}_{2}\right)$. The medium was changed 3 times a week and the cells were subcultivated every 14 days. In order to work with well differentiated cells, RPTEC were used for experiments from passage 5 to 9 [20]. These cells express the mRNA of organic anion transporters OCT 1 and OCT2 but not of OCT3 (SLC22A1, SLC22A2 and SLC22A3, resp.) as confirmed by PCR and qRT-PCR.

Determination of collagen secretion by direct ELISA

Collagen I, III and IV secretion was determined by enzyme-linked immunosorbent assay (ELISA). According to [31], media and collagen standards (Sigma) were incubated overnight at $4{ }^{\circ} \mathrm{C}$ in 96-well NuncImmuno Maxisorb plates (Nalge Nunc International, Naperville, IL, USA). Following washing and blocking (2 $\mathrm{h}$ in $2 \%$ bovine serum albumin in PBS/Tween $0.05 \%$ ), wells were incubated with rabbit antibody against collagen I, III or IV (1:1000, Rockland, Gilbertsville, PA) for $1 \mathrm{~h}$ at room temperature. After three washes, wells were incubated with HRP-conjugated secondary antibody (1:20000; Rockland, Gilbertsville, PA) for $1 \mathrm{~h}$ at room temperature and thereafter, after washing, incubated with $o$-phenylenediamine solution $(0.5$ $\mathrm{mM} o$-phenylenediamine, $150 \mathrm{mM} \mathrm{Na}_{2} \mathrm{HPO}_{4}, 3.5 \mathrm{mM}$ citric acid, $0.015 \% \mathrm{H}_{2} \mathrm{O}_{2}$ ) and the reaction was stopped after 15 min with $1 \mathrm{~N} \mathrm{H}_{2} \mathrm{SO}_{4}$. The absorbance at $490 \mathrm{~nm}$ was determined using a multiwell-multilabel reader (Viktor ${ }^{2}$, Wallac, Turku, Finland). Collagen secretion was normalized to total cellular protein content determined by the BCA-Assay [32].

Determination of intracellular collagen by western blotting

Cells were lysed in ice-cold buffer ( $1 \mathrm{mM}$ Na-orthovanadate, $1 \%$ Nonidet P- $40,0.1 \%$ SDS, $0.1 \%$ Triton $\mathrm{X}-100$, protease inhibitor cocktail, in PBS), protein therein determined and equal protein amounts were separated by SDS-PAGE and transferred onto a nitrocellulose membrane. Subsequently, membranes were blotted with either rabbit anti-collagen type III or IV antibody (1:1000, Rockland, Gilbertsville, PA via Biotrend, Cologne, Germany). The primary antibody was detected using horseradish-peroxidase-conjugated secondary IgG (1:20 000) visualized by ECL. Protein bands were quantified using SigmaGel software (Jandel Scientific).

\section{Determination of gelatinase activity}

Gelatinase activity in cell culture media was determined as described in [33]. Shortly, the media were incubated with reaction Buffer (0.05 M Tris-Base, $150 \mathrm{mM} \mathrm{NaCl}, 5 \mathrm{mM} \mathrm{CaCl}, 1 \mu \mathrm{M} \mathrm{ZnCl}_{2}, 0.2 \mathrm{mM} \mathrm{NaN}_{3}, \mathrm{pH}$ 7.6) and $1 \mu \mathrm{g}$ FITC-labeled-gelatin (DQ-gelatin). Increase in fluorescence over time was determined at 37 ${ }^{\circ} \mathrm{C}$ at 490/535 nm excitation/emission. 1-10 ng collagenase I (Clostridium histolyticum, Sigma) served as positive controls. The measured increase in fluorescence/time was normalized for protein content. Possible direct effects of CAA on collagenase I were also tested, since CAA is capable of direct modification of proteins [21]. We found no alterations in collagenase I activity after $4 \mathrm{~h}$ incubation of the enzyme with CAA up to 150 $\mu \mathrm{M}$.

\section{Determination of CA-074 sensitive gelatinase activity}

Contribution of cathepsin B to total gelatinase activity was determined by use of the cathepsin B inhibitor CA-074 (10 $\mu \mathrm{M}$; Sigma). As described in the previous paragraph, two aliquots from cell culture supernatants were incubated with gelatinase assay reaction buffer containing either CA-074 or DMSO. After addition of $1 \mu \mathrm{g}$ DQ-gelatine the effect of CA-074 on fluorescence increase over time was assessed. Fluorescence counts were normalized for control/DMSO and protein content. CA-074 did not affect the collagenase I controls.

\section{Gelatin zymography}

Gelatin zymography of cell culture media was performed using PAGE in $10 \%$ polyacrylamide gels containing $0.5 \%$ gelatin. Media $(50 \mu \mathrm{l})$ were incubated for $30 \mathrm{~min}$ at $37^{\circ} \mathrm{C}$ in Laemmli Buffer devoid of mercaptoethanol and subsequently underwent electrophoresis. Afterwards gels were washed in $2.5 \%$ Triton X-100 in $\mathrm{H}_{2} \mathrm{O}$ for $1 \mathrm{~h}$, followed by overnight incubation at $37^{\circ} \mathrm{C}$ in enzyme buffer (50 mM TRIS; 10 $\mathrm{mM} \mathrm{CaCl}, 1 \mu \mathrm{M} \mathrm{ZnCl}_{2}, 0.1 \%$ Triton X-100, $3 \mathrm{mM} \mathrm{NaN}_{3}, \mathrm{pH} 7.5$ ). After Comassie staining and destaining of the gels, areas of gelatinase activity appeared as nonstained, light bands. Afterwards, gels were dried, scanned and analyzed by SigmaGel-software. Intensity values were normalized to total cellular protein content. 


\section{Determination of Cathepsin B activity}

Cathepsin B activity was measured by means of the specific fluorescent substrate z-Arg-Arg-AMC (AMC: 7-amino-4-methyl-coumarin) [34]. After incubation for up to $3 \mathrm{~h}$ at $37^{\circ} \mathrm{C}$, fluorescence of the cleavage product AMC was measured at $355 \mathrm{~nm}$ excitation and $460 \mathrm{~nm}$ emission. Activity was normalized to protein content.

\section{PCR experiments}

The mRNA of organic anion transporters SLC22A1, SLC22A2 and SLC22A3 (OCT1, OCT2 and OCT3) was detected by PCR and qRT-PCR using the following conditions and primers: $10 \mathrm{~min} 95^{\circ} \mathrm{C}$ followed by 45 cycles with 10 seconds $95^{\circ} \mathrm{C}, 10$ seconds $60^{\circ} \mathrm{C}$ and 30 seconds $72^{\circ} \mathrm{C}$, in case of qRT-PCR followed by melting point determination. The quality of the primers $\left(5^{\prime}-3^{\prime}\right)$ has been validated by sequencing the unique amplificate found in cells overexpressing the resp. mRNAs.

SLC22A1 (OCT1), forward: ACATTCGTCAGGAACCTCGG

reverse: CGCCGCAAAACATCTCTCTC

SLC22A2 (OCT2), forward: GCTACGAGGTGGACTGGAAC

reverse: CTCCGATATCTCCGCCCAAC

SLC22A3 (OCT3), forward: GTTTTTGCTGCTGTGCCTGAC

reverse: TCCAGCATCCACGCATTGAC

\section{Statistics}

All data are presented as mean values \pm S.E.M. For statistical testing prophet 5.0 software was used. The Shapiro-Wilks-test was performed to test data for normality $\left(\mathrm{H}_{0}\right.$ was rejected when $\left.\mathrm{p}<0.05\right)$. When none of the tested samples failed the normality test, samples were compared by one-way ANOVA, otherwise by Kruskal-Wallis-test. Statistical significance was assumed when $\mathrm{p}<0.05$.

\section{Results}

Chloroacetaldehyde causes time- and dose-dependent alterations in extracellular matrix composition of renal cells

Following $24 \mathrm{~h}$ of serum starvation, human proximal tubule cells in primary culture were incubated for 24-48 h with CAA in concentrations from 15 up to $150 \mu \mathrm{M}$. According to literature, $15 \mu \mathrm{M}$ resemble CAA levels detected in patient plasma during ifosfamide therapy [35]. Figures $1 \mathrm{~A}$ and $\mathrm{B}$ show the effect of $15 \mu \mathrm{M}$ and $150 \mu \mathrm{M}$ CAA on extracellular matrix composition in RPTEC after $24 \mathrm{~h}$ and $48 \mathrm{~h}$ incubation. As shown in Figure 1A, $15 \mu \mathrm{M}$ CAA induced a progredient increase in type III collagen $(182.4 \pm 13.8 \%$ of control after $24 \mathrm{~h}$ and $266.4 \pm 46.2 \%$ of control after $48 \mathrm{~h})$, whereas collagen I was not affected $(123.1 \pm 9.1 \%$ of control after $24 \mathrm{~h}$ and $99.7 \pm 6.5 \%$ of control after $48 \mathrm{~h}$ ). Type IV collagen was reduced during the incubation period $(80.2 \pm 4.8 \%$ of control after $24 \mathrm{~h}$ and $82.3 \pm 5.4 \%$ of control after $48 \mathrm{~h}$ ). When RPTEC were challenged with $150 \mu \mathrm{M}$ CAA (Fig. 1B), a massive and progredient increase in secreted collagen III was observed (703.6 $\pm 108.2 \%$ of control after $24 \mathrm{~h}$ and $2286.2 \pm 834.1 \%$ of control after $48 \mathrm{~h}$ ). Collagen I secretion was elevated but failed to be statistically significant $(314.9 \pm 44.1 \%$ of control after $24 \mathrm{~h}$ and $302.1 \pm 107.8 \%$ of control after $48 \mathrm{~h}$ ). Also, collagen type IV secretion was elevated (135.0 $\pm 14.9 \%$ of control after 24 $\mathrm{h}$ and $214.3 \pm 82.6 \%$ of control after $48 \mathrm{~h}$ ). Yet, the effect of $150 \mu \mathrm{M}$ CAA on type IV collagen failed to reach statistical significance. The parent compound ifosfamide $(150 \mu \mathrm{M})$ and its metabolite acrolein $(15 \mu \mathrm{M})$ failed to interfere significantly with RPTEC collagen secretion (not shown). These data show that CAA at clinical relevant concentrations enhances collagen III secretion of human renal proximal tubule cells in primary culture.

Western blot analysis of lysates from RPTEC showed slightly increased intracellular levels of collagen type III (Fig. 1C: $148.0 \pm 27.2 \%$ of control after $24 \mathrm{~h}$ and $256.3 \pm 62.0 \%$ of control after $48 \mathrm{~h}$ ), whereas intracellular collagen IV was decreased after challenge with 15 $\mu \mathrm{M}$ CAA $(29.2 \pm 7.1 \%$ of control after $24 \mathrm{~h}$ and $40.2 \pm 16.1 \%$ of control after $48 \mathrm{~h})$. Thus, the results indicate that altered intracellular collagen metabolism is involved in the changes of secreted collagen pattern caused by CAA. 


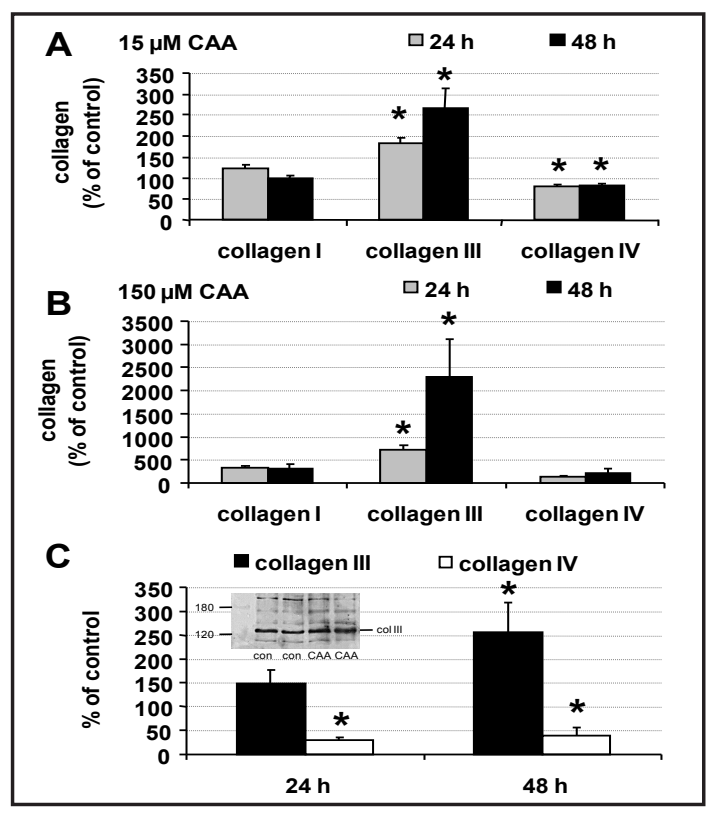

Fig. 1. Effects of CAA on collagen secretion and intracellular collagen III and collagen IV content of RPTEC. $15 \mu \mathrm{M}$ (A) or $150 \mu \mathrm{M}$ (B) CAA were applied and collagen content was determined in media after $24 \mathrm{~h}$ and $48 \mathrm{~h}$ of exposure ( $\mathrm{n}=16-48$; $^{*} \mathrm{p}<0.05$ vs. control). (C) Intracellular collagen content after exposure to $15 \mu \mathrm{M}$ CAA. Insert shows a representative western blot against collagen III after $24 \mathrm{~h} 15$ $\mu \mathrm{M}$ CAA ( $\mathrm{n}=4-7 ;^{*} \mathrm{p}<0.05$ vs. control).

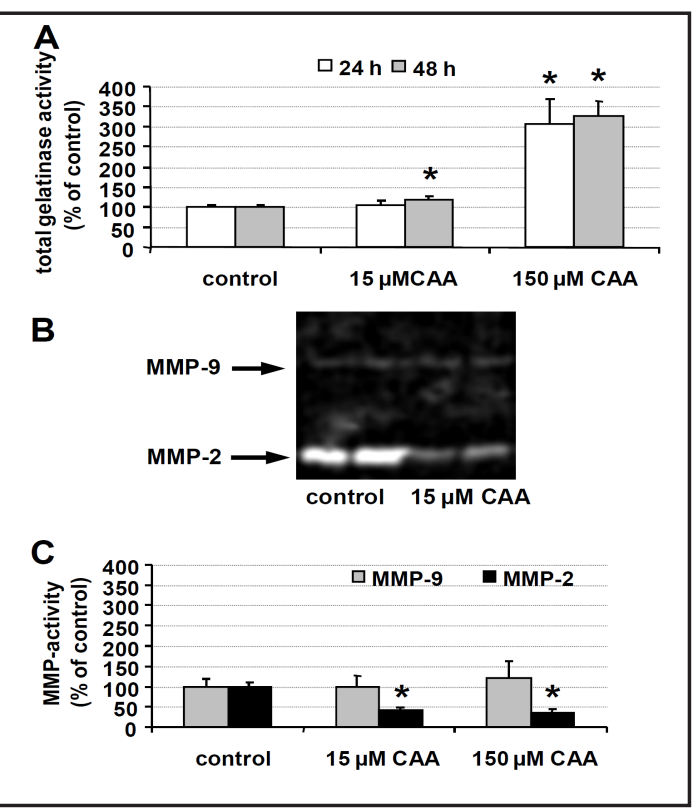

Fig. 2. (A) Total gelatinase activity in cell culture supernatants of RPTEC after $24 \mathrm{~h}$ and $48 \mathrm{~h}$ exposure to 15 or $150 \mu \mathrm{M}$ CAA ( $n=8-26$; ${ }^{*} \mathrm{p}<0.05$ vs. control). (B) Gelatin zymography of RPTEC media. Typical result with a faint gelatinolytic band representing MMP-9 and a solid band representing MMP2. (C) Quantification of MMP-2 and MMP-9 activity ( $\mathrm{n}=6-9 ;{ }^{*} \mathrm{p}<0.05$ vs. control).

Chloroacetaldehyde alters activities of secreted collagenolytic and gelatinolytic enzymes

To test a possible interference of CAA with enzymes involved in matrix degradation, gelatinase activity was determined in media collected after CAA exposure. Furthermore, gelatin zymography was used to specify MMP's possibly involved. Figure 2A shows that incubation with CAA caused an increase in total gelatinase activity $24 \mathrm{~h}$ after exposure of RPTEC to $150 \mu \mathrm{M}$ CAA. After exposure to $15 \mu \mathrm{M}$ CAA total gelatinase activity was slightly elevated after $48 \mathrm{~h}$ incubation (Fig. $2 \mathrm{~A}$; total gelatinase activity: $106.6 \pm 7.9 \%$ of control after $24 \mathrm{~h}$ and $118.8 \pm 8.4 \%$ of control after $48 \mathrm{~h}$ ). $150 \mu \mathrm{M}$ CAA led to an elevation of total gelatinase activity to $307.2 \pm 60.0 \%$ of control after $24 \mathrm{~h}$ and $327.1 \pm 36.7 \%$ of control after $48 \mathrm{~h}$, respectively. In the additionally performed gelatin zymography experiments (Fig. 2B and C) MMP-2 and MMP-9 were found to be predominantly secreted by RPTECs, with much higher MMP-2 activity rates than MMP-9 activity. The faint gelatinolytic band representing weak MMP-9 activity was unaltered by CAA treatment. To our surprise, MMP-2 activity was significantly reduced after CAA exposure for $24 \mathrm{~h}$ or $48 \mathrm{~h}(15 \mu \mathrm{M}$ CAA reduced relative MMP2 activity to $41.1 \pm 6.6 \%$ of control after $24 \mathrm{~h}$ and to $33.8 \pm 10.0 \%$ of control after $48 \mathrm{~h}$ ). In order to explain this discrepancy between the induction of total gelatinase activity and reduction of MMP-2 activity, we investigated the contribution of the lysosomal protease cathepsin B in CAA-treated RPTECs. Since CAA induces lysosomal protein overload and leakage of lysosomes [21], we further investigated the sensitivity of total gelatinase activity against the specific cathepsin B inhibitor CA-074. As shown in Figure 3A, CA-074 $(10 \mu \mathrm{M})$ led to a significant reduction of total gelatinase activity in media of CAA-treated cells $(15 \mu \mathrm{M}$ CAA: $111.9 \pm 14.6$ vs. $77.5 \pm 11.4 \%$ of control; $150 \mu$ M CAA: $182.0 \pm 19.8$ vs. $101.4 \pm 18.8 \%$ of control), whereas no significant effect of CA-074 in media of control cells was observable $(92.7 \pm 6.4 \%$ of control). To support this hypothesis, cathepsin B activity in cell culture 


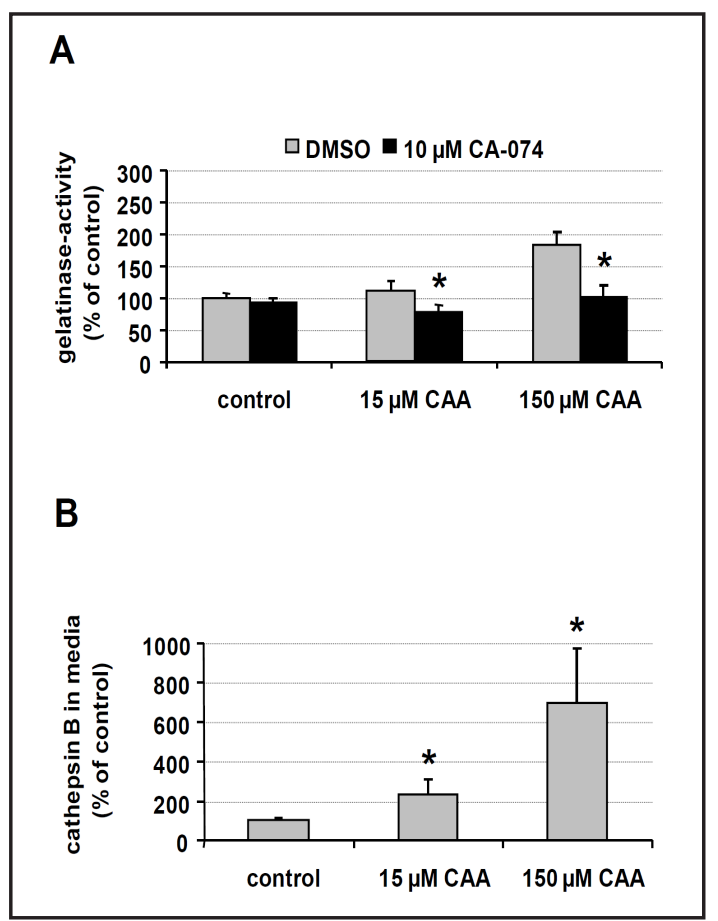

Fig. 3. (A) Total gelatinase activity after 48 hours in cell culture supernatants of RPTEC in presence and absence of the cathepsin B inhibitor CA-074 ( $\mathrm{n}=16$ - 20; ${ }^{*} \mathrm{p}<0.05$ vs. DMSO; n.s. = not significant). (B) Cathepsin B activity in RPTEC media after 48 hours ( $\mathrm{n}=12-16 ;{ }^{*} \mathrm{p}<0.05$ vs. control).

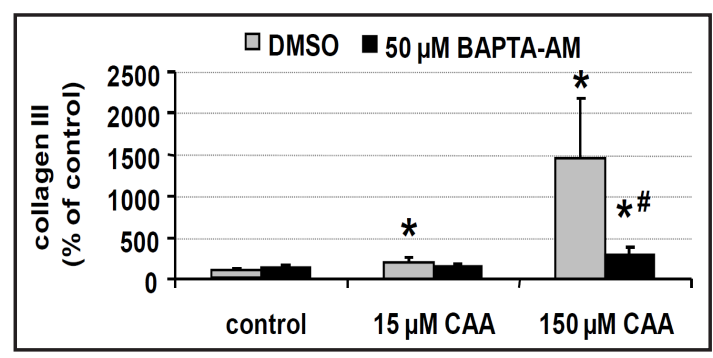

Fig. 4. Effect of calcium chelation by BAPTA-AM (50 $\mu \mathrm{M})$ on CAA-induced collagen III secretion after 48 hours ( $\mathrm{n}=8$; ${ }^{*} \mathrm{p}<0.05$ vs. control; \# $\mathrm{p}<0.05$ vs. 150 $\mu \mathrm{M}$ CAA).

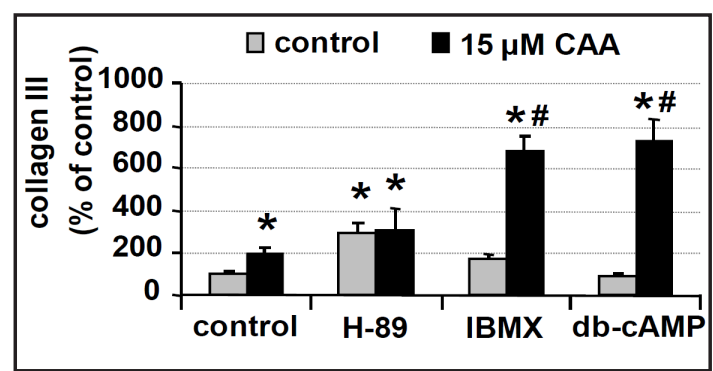

Fig. 5. Influence of PKA-cAMP-signaling pathway on CAA-induced collagen III secretion. Cells were incubated for 48 hours with or without $15 \mu \mathrm{M}$ CAA and $1 \mu \mathrm{M} \mathrm{H}-89,500 \mu \mathrm{M}$ IBMX or $1 \mathrm{mM}$ cAMP ( $n=6-8$; $^{*} \mathrm{p}<0.05$ vs. control; \# $\mathrm{p}<0.05$ vs. $15 \mu \mathrm{M}$ CAA).

media was determined. As shown in Figure 3B, a significant increase in media cathepsin B activity induced by CAA occurred $(15 \mu \mathrm{M}: 230.9 \pm 77.7 \%$ of control; $150 \mu \mathrm{M}: 702.1 \pm 273.9$ $\%$ of control). Under control conditions, media cathepsin B release was $0.44 \pm 0.05 \%$ of total cathepsin B activity. Thus, CAA inhibits MMP-2-activity, but due to concomitant cathepsin B leakage from the cells, total gelatinase activity is unchanged (15 $\mu \mathrm{M}$ CAA) or even enhanced $(150 \mu \mathrm{M}$ CAA). These data reveal a severe interaction of CAA with ECM turnover, since not only collagen secretion is disturbed by CAA, but also the balance of secreted matrixremodelling enzyme activities is heavily disordered.

\section{Contribution of signaling pathways in CAA induced matrix derangement}

Calcium and PKC

To identify mechanisms by which CAA affects ECM homeostasis of RPTEC, pharmacological approaches were used. Collagen III secretion by RPTEC was used as surrogate marker, because it was the most sensitive parameter after CAA treatment. Since CAA induces sustained increases of intracellular $\mathrm{Ca}^{2+}$ in RPTECs [20], the effect of intracellular $\mathrm{Ca}^{2+}$ chelation with BAPTA-AM on CAA induced collagen III secretion was examined. Incubation of RPTEC with BAPTA-AM $(50 \mu \mathrm{M})$ reduced CAA induced collagen III secretion after $48 \mathrm{~h}$ incubation (Fig. 4). The use of the PKC inhibitors BIM I (500 nM) and rottlerin $(10 \mu \mathrm{M})$ had no effect (data not shown). Thus, the effect of CAA on collagen type III secretion seems to be dependent on intracellular $\mathrm{Ca}^{2+}$ but not on PKC activation.

Role of PKA and cAMP signaling pathways

Earlier studies from our laboratory could show a dependence of CAA-induced $\mathrm{Ca}^{2+}$ elevations in RPTEC on cAMP/PKA-signaling [20]. Therefore, the impact of the membrane 
Fig. 6. Extracellular pH-dependent CAAevoked collagen III secretion after 48 hours. ( $\mathrm{n}=6-14 ;{ }^{*} \mathrm{p}<0.05$ vs. control; \# $\mathrm{p}<0.05$ vs. 150 $\mu \mathrm{M}$ CAA).

Fig. 7. Effect of protein load on CAA-induced collagen III formation. RPTEC were incubated with 15 or $150 \mu \mathrm{M}$ CAA for $24 \mathrm{~h}$ and afterwards challenged with $1 \mathrm{~g} / \mathrm{l}$ bovine serum albumin (BSA / BSA+CAA) for another $24 \mathrm{~h}$ ( $\mathrm{n}=8$; $* \mathrm{p}<0.05$ vs. control; \# $\mathrm{p}<0.05$ vs. CAA).
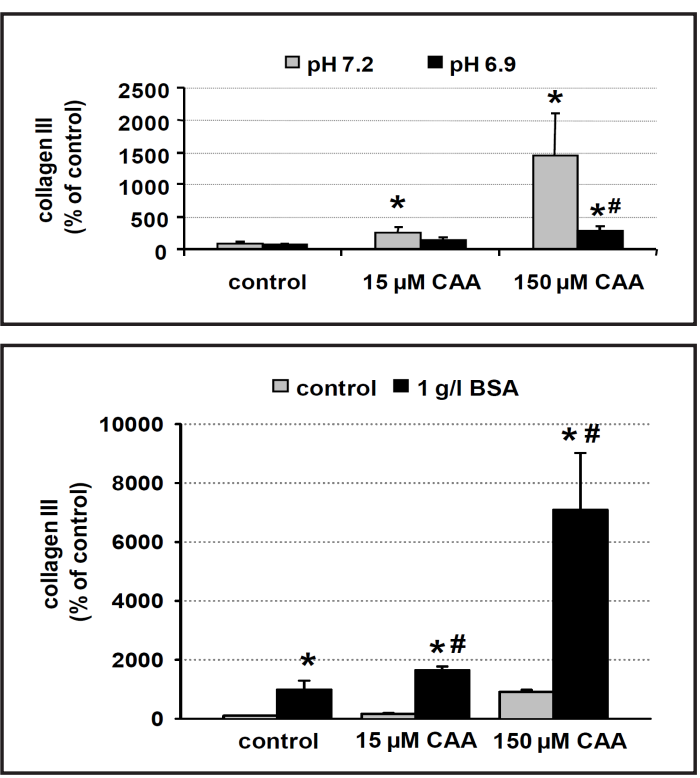

permeable cAMP-analogue dibutyryl-cAMP (db-cAMP; $1 \mathrm{mM}$ ), the phosphodiesteraseinhibitor IBMX (isobutylmethylxanthine $0.5 \mathrm{mM}$ ) and the PKA-inhibitor H-89 $(1 \mu \mathrm{M})$ were tested on collagen III secretion by RPTEC. Figure 5 shows the effects of H-89, IBMX and dbcAMP on collagen III secretion in the presence or absence of $15 \mu \mathrm{M}$ CAA. $48 \mathrm{~h}$ incubation with $\mathrm{H}-89$ alone led to a significant increase in collagen type III production $(295.7 \pm 50.5 \%$ of control), that was not further increased by CAA (306.8 $\pm 96.8 \%$ of control). IBMX (168.9 $\pm 26.2 \%$ of control) and db-cAMP (88.7 $\pm 12.2 \%$ of control) did not significantly alter the amount of secreted collagen III, whereas both compounds potentiated the effect of CAA: IBMX + CAA increased type III collagen to $679.1 \pm 66.0 \%$ of control whereas CAA alone led to an increase to $194.5 \pm 28.7 \%$ of control. Coincubation of CAA and dibutyryl-cAMP elevated collagen III secretion to $730.8 \pm 99.4 \%$ of control. Thus, there is evidence for a contribution of the cAMP/PKA-signaling pathway in CAA-induced collagen type III secretion.

\section{Extracellular $p H$ and sulfhydryl-ractivity}

Since acute CAA toxicity can be partly reduced by extracellular acidification due to reduced sulfhydryl reactivity of the compound in acidic environment [21], the effects of lowering extracellular $\mathrm{pH}$ on collagen III secretion provoked by CAA was investigated. Figure 6 shows the amount of extracellular collagen III in acidified media $\left(\mathrm{pH}_{0} 7.2\right.$ or 6.9) of RPTEC after $48 \mathrm{~h}$ CAA exposure. The extracellular acidification per se had no significant effect on collagen type III secretion. At $\mathrm{pH}_{0} 7.2,15 \mu \mathrm{M}$ CAA led to an increase of collagen III to $245 \pm$ $100 \%$ of control and to $1445 \pm 666 \%$ of control when $150 \mu \mathrm{M}$ CAA were used. At $\mathrm{pH}_{\mathrm{o}} 6.9$, collagen III secretion was $150 \pm 50 \%$ of control in presence of $15 \mu \mathrm{M}$ CAA and $278 \pm 89 \%$ of control after challenge with $150 \mu \mathrm{M}$ CAA. These results indicate a reduced effect of CAA on collagen type III secretion in an acidic extracellular environment.

\section{Protein challenge aggravates CAA-induced collagen III increase}

The effects of CAA with regards to changes in lysosomal morphology and permeability could be enhanced by additional protein challenge [21]. Therefore, a possible contribution of an elevated protein load on collagen III secretion in response to CAA was investigated. After $24 \mathrm{~h}$ exposure to 15 or $150 \mu \mathrm{M}$ CAA, RPTEC were challenged by $1 \mathrm{~g} / \mathrm{l}$ bovine serum albumin for additional $24 \mathrm{~h}$. The results are summarized in Figure 7 . BSA alone led to an increase in type III collagen to $986 \pm 325 \%$ of control according to known effects of protein challenge on proximal tubule cells [36]. Addition of BSA to cells exposed to CAA induced an increase of collagen III already at $15 \mu \mathrm{M}$ CAA and up to $7093 \pm 2058 \%$ of control $(150 \mu \mathrm{M} \mathrm{CAA})$. Thus, CAA-induced collagen III secretion can be potentiated by protein overload. 
Fig. 8. Scheme of the putative profibrotic action mechanism of CAA. 1: CAA disturbs signaling via cAMPPKA and intracellular $\mathrm{Ca}^{2+}$ leading to an increase of intracellular collagen III. 2. CAA induces lysosomal protein overload and leakage, further promoting collagen synthesis. Cathepsin B released from lysosomes cleaves intra- and extracellular collagen IV. 3. Reduced MMP-2 activity further aggravates extracellular collagen III accumulation. Extracellular cathepsin B exacerbates ECM disturbance by further collagen IV depletion.

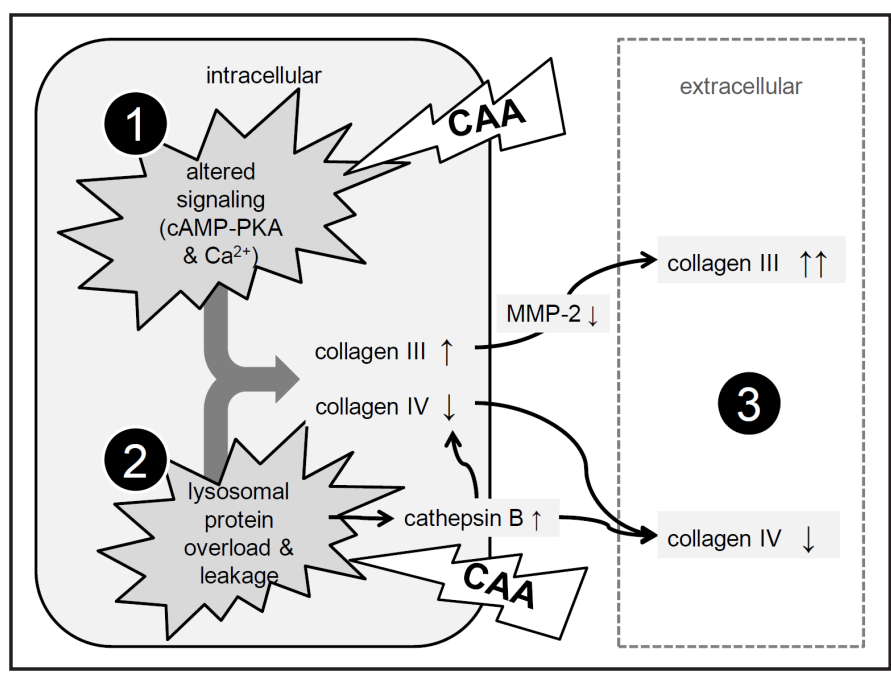

Table 1. Summary of CAA effects on the parameters tested in this study

\begin{tabular}{lc}
\hline & effect \\
\hline Collagen III (intracellular) & $\uparrow$ \\
Collagen III (extracellular) & $\uparrow$ \\
Collagen IV (intracellular) & $\downarrow$ \\
Collagen IV (extracellular) & $\downarrow$ \\
MMP2 activity & $\downarrow$ \\
MMP9 activity & \pm \\
Cathepsin B activity (intracellular) & $\downarrow$ \\
Cathepsin B activity (extracellular) & $\uparrow$ \\
\hline
\end{tabular}

\section{Discussion}

The data presented here show that the ifosfamide metabolite chloroacetaldehyde is a potent profibrotic agent in renal proximal tubule cells in primary culture. We tested also its parent compound, ifosfamide, which turned out to have no profibrotic action although we were able to demonstrate the mRNA expression of IFO-transporting organic cation transporters [37] SLC22A1 and SLC22A2 (OCT1 and 2) but not SLC22A3 (OCT3) and although the presence of certain IFO-metabolizing cytochrome P450 enzymes at least in tubular cells of the developing kidney has been shown [13]. Obviously, either ifosfamide was not taken up sufficiently or not metabolized to a sufficient amount to exert the effects which has CAA on extracellular matrix homeostasis described here.

The effect of CAA is predominantly characterized by a marked increase in type III collagen synthesis and a decrease in type IV collagen in cells of proximal tubule origin. These data point towards extracellular matrix disarrangement provoked by CAA, which on the one hand leads to deposition of fibrillar collagen type III, associated with fibrosis, inflammatory events and wound healing. The decrease in type IV collagen could reflect reduction of epithelial tightness by impaired composition of basal membranes, negatively influencing tubular transport mechanisms. These results are in good agreement with case reports from patients who developed chronic ifosfamide nephrotoxicity presenting as tubulointerstitial fibrosis [25-27].

To distinguish between enhanced synthesis of type III collagen and reduction in matrix degradation induced by CAA, western blot analysis of intracellular collagen was performed and gelatinase/matrix metalloproteinase activity in media of CAA treated cells was determined. The data show that CAA exposure led to an increase of intracellular collagen III as well as a reduction in intracellular collagen IV immunoreactivity, in accordance to extracellular matrix alteration evoked by CAA. Total gelatinolytic capacity, determined by gelatinase-assay, was 
not reduced by CAA. Nevertheless MMP-2 activity, determined by gelatin zymography was reduced. These apparently conflicting results can be explained by increased cathepsin $B$ activity in RPTEC supernatants, most probably due to release of cathepsins from ruptured lysosomes as well as other collagenolytic proteases that can access the extracellular space due to CAA-induced membrane disruption. The increased cathepsin B activity measured in RPTEC media after CAA exposure coincided with an increasing fraction of gelatinase sensitive to the specific cathepsin B-inhibitor CA-074. In a previous study, we could show lysosomal leakage after CAA exposure in coincidence with increased cell membrane permeability [21]. It is known, that amongst lysosomal proteases especially cathepsin B can be stable and active in the extracellular space under non-acidic conditions [38].

As shown previously [20], CAA is capable to interfere with $\mathrm{Ca}^{2+}$ - and cAMP-PKA-signaling. Thus, the possible contribution of these signaling pathways on CAA-induced collagen type III synthesis was investigated. Chelation of intracellular free $\mathrm{Ca}^{2+}$ by BAPTA-AM reduced collagen III accumulation in response to CAA. These results point towards an involvement of $\mathrm{Ca}^{2+}$ in the fibrotic action of CAA probably including calcium-dependent kinases or calciumcalmodulin complexes. Furthermore, chelation of $\mathrm{Ca}^{2+}$ by BAPTA-AM is able to reduce the CAA-invoked collagen III synthesis even when CAA is used in a concentration of $150 \mu \mathrm{M}$. Since $\mathrm{Ca}^{2+}$-chelation prevents protein loss induced by $15 \mu \mathrm{M}$ CAA, but not by $150 \mu \mathrm{M}$ CAA [20], it can be speculated that $\mathrm{Ca}^{2+}$ is a signal transducer for chronic CAA effects, such as fibrosis, but not for the toxic effects of high CAA concentrations that are most probably a direct effect of thiol-group depletion [23]. Additionally, involvement of the cAMP-PKApathway in enhanced collagen III formation was investigated. Inhibition of PKA by H-89 abrogated the effect of CAA on collagen type III, whereas stimulation of adenylyl cylclase by db-cAMP and inhibition of phosphodiesterases by IBMX potentiated CAA-induced collagen III synthesis. These data implicate that the cAMP-PKA pathway is involved in the increased extracellular type III collagen secretion in response to CAA.

In order to investigate the possibility that extracellular acidification could be a prevention method for the profibrotic effects of CAA, the effect of CAA on collagen III was determined after lowering extracellular $\mathrm{pH}$. As previously reported, the ability of CAA to react with sulfhydryl groups is reduced by acidification in vitro [21]. Reducing extracellular $\mathrm{pH}$ from 7.2 to 6.9 diminishes the profibrotic action of CAA. This is most probably due to impaired SH-reactivity by CAA. In addition, inhibition of cathepsin B activity by CAA is lessened when cells are exposed to CAA in acidic media. Taken together, these results point towards SHreactivity of CAA as a cause for the fibrotic effects, especially inhibition of lysosomal protein degradation which leads to cellular protein overload.

Additionally, protein overload can contribute to chronic renal damage by CAA. When human proximal tubule cells are challenged with BSA after CAA exposure, the profibrotic effects of CAA are potentiated, indicating that inhibition of lysosomal cysteine proteases by CAA worsens the effect of protein challenge. Thus, there is evidence for disturbed protein handling by proximal tubular cells after CAA exposure. In proteinuria-induced proximal tubular damage, free radicals play a major role in progression of fibrosis. In order to test the contribution of free radicals to CAA-induced type III collagen synthesis, the radical scavenger tiron was used. In these experiments, no positive effect of tiron could be observed on collagen III accumulation as well on LDH-release (data not shown). These results are in accordance with data published on CAA-toxicity in osteosarcoma cells [22].

In conclusion, this study shows that the ifosfamide metabolite CAA is able to induce extracellular matrix alterations in human proximal tubule cells in primary culture. The predominant feature is an increase in collagen III, which is due to enhanced synthesis of type III collagen accompanied by a decrease in MMP-2 activity. The effect of CAA on collagen III depends on intracellular free $\mathrm{Ca}^{2+}$ and cAMP-PKA signaling. Protein challenge aggravates the fibrotic effect of CAA. Reducing sulfhydryl reactivity of CAA by acidification ameliorates CAA-induced fibrosis. Thus, there is evidence for chronic alterations in proximal tubule cell homeostasis by CAA that could translate into the clinically observed chronic and progredient course of ifosfamide nephropathy. 
Benesic et al.: Chloroacetaldehyde Disrupts Renal Matrix Homeostasis

\section{Acknowledgements}

We thank Hildegard Holzinger and Ruth Freudinger for their excellent technical assistance. This study was supported by the Deutsche Forschungsgemeinschaft (grant DFG Be 3618/1-1 and 1-2).

\section{Disclosure Statement}

The authors have no conflict of interests.

\section{References}

1 Kerbusch T, de Kraker J Keizer, HJ, van Putten JW, Groen HJ, Jansen RL, Schellens JH, Beijnen JH: Clinical pharmacokinetics and pharmacodynamics of ifosfamide and its metabolites. Clin Pharmacokinet 2001;40:41-62. Carli M, Passone E, Perilongo G, Bisogno G: Ifosfamide in pediatric solid tumors. Oncology 2003;65:99-104. Skinner R: Chronic ifosfamide nephrotoxicity in children. Med Pediatr Oncol 2003;41:190-197.

Ferrari S, Pieretti F, Verri E, Tolentinis L, Cesari M, Versari M, Zolezzi C, Lamanna G, Bacci G: Prospective evaluation of renal function in pediatric and adult patients treated with high-dose ifosfamide, cisplatin and high-dose methotrexate. Anticancer Drugs 2005;16:733-738.

5 Klastersky J: Side effects of ifosfamide. Oncology 2003;65:7-10.

6 Skinner R: Nephrotoxicity--what do we know and what don't we know? J Pediatr Hematol Oncol 2011;33:128-134.

7 Loebstein R, Atanackovic G, Bishai R, Wolpin J, Khattak S, Hashemi G, Gobrial M, Baruchel S, Ito S, Koren G: Risk factors for long-term outcome of ifosfamide-induced nephrotoxicity in children. J Clin Pharmacol 1999;39:454-461.

8 Hanly L, Chen N, Rieder M, Koren G: Ifosfamide nephrotoxicity in children: a mechanistic base for pharmacological prevention. Expert Opin Drug Saf 2009;8:155-168.

-9 Skinner R, Parry A, Price L, Cole M, Craft AW, Pearson AD: Glomerular toxicity persists 10 years after ifosfamide treatment in childhood and is not predictable by age or dose. Pediatr Blood Cancer 2010;54:983-989.

10 Ho PT, Zimmerman K, Wexler LH, Blaney S, Jarosinski P, Weaver-McClure L, Izraeli S, Balis FM: A prospective evaluation of ifosfamide-related nephrotoxicity in children and young adults. Cancer 1995;76:2557-2564.

-11 Zaki EL, Springate JE, Taub M: Comparative toxicity of ifosfamide metabolites and protective effect of mesna and amifostine in cultured renal tubule cells. Toxicol In Vitro 2003;17:397-402.

12 Aleksa K, Halachmi N, Ito S, Koren G: A tubule cell model for ifosfamide nephrotoxicity. Can J Physiol Pharmacol 2005;83:499-508.

13 Aleksa K, Matsell D, Krausz K, Gelboin H, Ito S, Koren G: Cytochrome P450 3A and 2B6 in the developing kidney: implications for ifosfamide nephrotoxicity. Pediatr Nephrol 2005;20:872-885.

14 Springate JE: Ifosfamide metabolite chloroacetaldehyde causes renal dysfunction in vivo. J Appl Toxicol 1997;17:75-79.

15 Mohrmann M, Pauli A, Ritzer M, Schonfeld B, Seifert B, Brandis M: Inhibition of sodium-dependent transport systems in LLC-PK1 cells by metabolites of ifosfamide. Ren Physiol Biochem 1992;15:289-301.

16 Mohrmann M, Pauli A, Walkenhorst H, Schonfeld B, Brandis M: Effect of ifosfamide metabolites on sodiumdependent phosphate transport in a model of proximal tubular cells (LLC-PK1) in culture. Ren Physiol Biochem 1993;16:285-298.

17 Patzer, L Hernando N, Ziegler U, Beck-Schimmer B, Biber J, Murer H: Ifosfamide metabolites CAA, 4-OHIfo and Ifo-mustard reduce apical phosphate transport by changing NaPi-IIa in OK cells. Kidney Int 2006;70:1725-1734. 
Benesic et al.: Chloroacetaldehyde Disrupts Renal Matrix Homeostasis

18 Springate J, Taub M: Ifosfamide toxicity in cultured proximal renal tubule cells. Pediatr Nephrol 2007;22:358-365.

-19 Schwerdt G, Gordjani N, Freudinger R, Wollny, B, Kirchhoff A, Gekle M: Chloroacetaldehyde and acroleininduced death of human proximal tubule cells. Pediatr Nephrol 2006;21:60-67.

20 Benesic A, Schwerdt G, Mildenberger S, Freudinger R, Gordjani N, Gekle M: Disturbed Ca ${ }^{2+-}$ signalling by chloroacetalehyde: a possible cause for chronic ifosfamide nephrotoxicity. Kidney Int 2005;68:2029-2041.

21 Benesic A, Schwerdt G, Freudinger R, Mildenberger S, Groezinger F, Wollny B, Kirchhoff A, Gekle M: Chloroacetaldehyde as a sulfhydryl-reagent: The role of critical thiol-groups in ifosfamide nephropathy. Kidney Blood Press Res 2006;29:280-293.

-22 Takahashi K, Sakurai K, Takahashi K, Tanaka H, Fujimoto Y: Necrotic pathway in human osteosarcoma Saos2 cell death induced by chloroacetaldehyde. Anticancer Drugs 2007;18:543-553.

23 Schwerdt G, Kirchhof, A, Freudinger R, Wollny B, Benesic A, Gekle M: Mesna or cysteine prevent chloroacetaldehyde-induced cell death of human proximal tubule cells. Pediatr Nephrol 2007;22:798-803.

24 Hanly L, Rieder MJ, Huang SH, Vasylyeva TL, Shah RK, Regueira O, Koren G: N-acetylcysteine rescue protocol for nephrotoxicity in children caused by ifosfamide. J Popul Ther Clin Pharmacol 2013;20:e132-e145.

25 Friedlaender MM, Haviv YS, Rosenmann E, Peylan-Ramu N: End-stage renal interstitial fibrosis in an adult ten years after ifosfamide therapy. Am J Nephrol 1998;18:131-133.

-26 Berns JS, Haghighat A, Staddon A, Cohen RM, Schmidt R, Fisher S, Rudnick MR, Tomaszewski JE: Severe, irreversible renal failure after ifosfamide treatment. A clinicopathologic report of two patients. Cancer 1995;76:497-500.

27 Hill PA, Prince HM, Power DA: Tubulointerstitial nephritis following high-dose ifosfamide in three breast cancer patients. Pathology 2000;32:166-170.

-28 Harris DC: Tubulointerstitial renal disease. Curr Opin Nephrol Hypertens 2001;10:303-313.

29 Liu Y: Renal fibrosis: new insights into the pathogenesis and therapeutics. Kidney Int 2006;69:213-217.

-30 Zhou G, Li C, Cai L: Advanced glycation end-products induce connective tissue growth factor-mediated renal fibrosis predominantly through transforming growth factor beta-independent pathway. Am J Pathol 2004;165:2033-2043.

- 31 Gekle M, Knaus P, Nielsen R, Mildenberger S, Freudinger R, Wohlfarth V, Sauvant C, Christensen EI: Transforming growth factor-beta1 reduces megalin- and cubilin-mediated endocytosis of albumin in proximal-tubule-derived opossum kidney cells. J Physiol 2003;552:471-481.

-32 Lane RD, Federman D, Flora JL, Beck BL: Computer-assisted determination of protein concentrations from dye-binding and bicinchoninic acid protein assays performed in microtiter plates. J Immunol Methods 1986;92:261-270.

-33 Wohlfarth V, Drumm K, Mildenberger S, Freudinger R, Gekle M: Protein uptake disturbs collagen homeostasis in proximal tubule-derived cells. Kidney Int 2003;S103-S109.

-34 Sebekova K, Schinzel R, Ling H, Simm A, Xiang G, Gekle M, Munch G, Vamvakas S, Heidland A: Advanced glycated albumin impairs protein degradation in the kidney proximal tubules cell line LLC-PK1. Cell Mol Biol 1998;44:1051-1060.

-35 Pendyala L, Creaven PJ, Schwartz G, Meropol NJ, Bolanowska-Higdon W, Zdanowicz J, Murphy M, Perez R: Intravenous ifosfamide/mesna is associated with depletion of plasma thiols without depletion of leukocyte glutathione. Clin Cancer Res 2000;6:1314-1321.

-36 Imai E, Nakajima H, Kaimori JY: Albumin turns on a vicious spiral of oxidative stress in renal proximal tubules. Kidney Int 2004;66:2085-2087.

-37 Ciarimboli G, Holle SK, Vollenbrocker B, Hagos Y, Reuter S, Burckhardt G, Bierer S, Herrmann E, Pavenstadt H, Rossi R, Kleta R, Schlatter E: New clues for nephrotoxicity induced by ifosfamide: preferential renal uptake via the human organic cation transporter 2. Mol Pharm 2011;8:270-279.

38 Almeida PC, Nantes IL, Chagas JR, Rizzi CC, Faljoni-Alario A, Carmona E, Juliano L, Nader HB, Tersariol IL: Cathepsin B activity regulation. Heparin-like glycosaminogylcans protect human cathepsin B from alkaline pH-induced inactivation. J Biol Chem 2001;276:944-951. 